\title{
COVID-19 opens a window of reflection for comparative health systems and global health research
}

\section{Tuba i. Ağartan}

\begin{abstract}
The Covid-19 crisis that led to the loss of thousands of lives and initiated one of the most complex social and economic upheavals has also a created a window of reflection for health systems researchers to revisit our major concepts, frameworks, and underlying assumptions. This commentary reviews two literatures that remain rather separate: comparative health policy and global health. First, I examine whether convergence in circumstances brought about by the spread of Covid-19 creates opportunities for learning "about" as well as unpacking the motivations of policy actors and how they use the cross-national information. However, given the emphasis on national policy actors and processes, this literature may overlook the importance of global actors, institutions and ideas. Second, global health differentiates itself with an emphasis on multilateralism as a political positioning and its multidisciplinary and multi-sectoral approach. However, the global health field is also challenged to consider its mission, political standing on multilateralism, changing relationships between North and South and its commitment to multidisciplinary approach. I argue that health systems scholars should use the window of opportunity created by Covid-19 pandemic to reexamine their methodologies and rearticulate their positioning by acknowledging the voice and agency of the Global South.
\end{abstract}

Keywords: Covid-19; global health; comparative bealth policy; policy learning; multilateralism

Since its discovery in December 2019, the severe acute respiratory syndrome coronavirus 2 (SARS-CoV-2) or COVID-19 has been rapidly spreading across the globe, accompanied by waves of heated debates about responses

Tuba İ. Ağartan, Health Policy and Management, Providence College, 1 Cunningham Square, Providence Rhode Island 02918, USA, Email: tagartan@providence.edu. 
at local, national, and global policy scales. Faced with a common threat, researchers, policymakers, and media have been looking across national borders to see what others are doing to control its spread and to deal with its wide-ranging impacts on our health care systems, economies, and social relations. As expected, rankings of the highest number of deaths or most widespread testing emerged alongside debates on which countries are doing a better job and why. A rapidly growing body of comparative analysis, published in academic journals as well as the media, aims to answer these questions, summarizing individual country responses and comparing them with others. So, what does the COVID-19 crisis tell us about health care systems and their transformation in the process of globalization? In answering this question, the first theme I would like to explore in this commentary involves the role of comparative thinking in the public policy literature and health systems research, especially in contexts of crisis. Here, I examine whether convergence in circumstances brought about by the spread of COVID-19 creates opportunities for learning about as well as transferring and applying lessons from abroad. This question on policy learning and diffusion also allows us to unpack the motivations of policy actors and how they use cross-national information in diverse ways within the domestic policy context.

The COVID-19 crisis that led to the loss of thousands of lives and initiated one of the most complex social and economic upheavals ever experienced has also created a window of reflection for global health researchers to revisit our major concepts, frameworks, and underlying assumptions. This is the second theme in this commentary, which allows us to explore the key characteristics of the global health field and how it might differentiate itself from international health. While comparative health policy and global health literatures both build on similar social science disciplines (political science and international relations, sociology, history, anthropology, economics, etc.) and overlap especially in areas such as healthcare reforms and policy diffusion, there are important differences in perspective and methodology. As these literatures help us assess the COVID-19 crisis and hopefully shape the key policy steps, it is important to reflect on how they relate to each other and how they contribute to our understanding of population health and health systems. Before engaging with these theoretical debates, the next section reviews what COVID-19 has revealed about health systems.

\section{What has COVID-19 revealed about health systems?}

Despite all the warnings from the public health community about the high risks associated with infectious diseases and their possible disastrous impacts, 
most countries were not prepared for the COVID-19 pandemic. It was shocking to many that the National Health Services (NHS) in Britain that serves as an ideal type in health systems research has failed so miserably, with no sufficient stockpile of personal protective gear or clear plan for testing, tracing, and isolating. The United States spends about 18 percent of its gross domestic product on healthcare but did not have testing equipment or laboratories ready; in the early days of the pandemic its hospitals did not have enough intensive care unit (ICU) beds or personal protective gear to protect its healthcare workers. Given the accumulated global experience on infectious disease control and quick policy guidance put forward by the World Health Organization (WHO), why wouldn't British or US governments follow world-standard advice? At the global and/or regional levels, why didn't we have stockpiles to send to countries - high, middle, or low income - but instead witnessed high-income countries competing to purchase the needed equipment or medications in the global marketplace, thus depriving others?

Public health experts and the global health community have developed effective disease control tools but one of the clear lessons of the current pandemic experience is the large gap between accumulated public health knowledge and practice. Early experiences in China and Italy shocked the world and initiated a debate on how to cope with the pandemic effectively across local, national, regional, and global levels: when and how to close the borders, what the boundaries between rights and limitations are, and what happens to vulnerable populations that are subject to higher risks due to their preexisting conditions or living conditions (such as refugee camps, nursing homes, prisons, etc.). Racial and gender inequalities impacted the distribution of COVID-19, often overlapping with income disparities and availability of resources in communities. Many people also realized, perhaps for the first time, what public health agencies do at national (i.e. the Korea Centers for Disease Control and Prevention), regional (Africa Centres for Disease Control and Prevention), and global (WHO) levels. A much-needed debate on preparedness, institutional capacity, and learning from previous mistakes (as in the case of South Korea that has developed a public health infrastructure in the light of its experience with the MERS epidemic in 2015) has ensued. But it is still not clear how public health systems are organized and how they should be connected to healthcare (medical) systems.

What is clear is that countries with a robust public health infrastructure responded quickly and effectively to the virus. The United States serves as an interesting case study in this respect: it has the scientific expertise and basic infrastructure - Centers for Disease Control and Prevention (CDC), Federal Emergency Management Agency, Food and Drug Administration, and National Institutes of Health (NIH) at the federal level and state health 
departments at the local level - and yet decades of underfunding and recent cuts $^{1}$ have crippled its COVID-19 response. The list is too long to discuss here but we can highlight the errors in the tests developed earlier in the pandemic, the hesitancy to introduce swift disease control protocols such as largescale testing, contact tracing, and isolation, and lack of coordination at many levels. Countries such as South Korea and Singapore demonstrated that extensive early testing in the epidemic is effective only when it is combined with rigorous contact tracing, and effective communication that collects and disseminates information on the movements of potentially infected people. ${ }^{2}$ Therefore, global health experts highlighted building a robust public health infrastructure as a key lesson from COVID-19. For instance, in the case of India, Sridhar (2020) identified "hiring epidemiologists, data scientists, and immunologists, and strengthening health information systems" ${ }^{13}$ as key steps to prepare for the next pandemic.

A health system consists of all organizations, people, and actions whose primary intent is to promote, restore, or maintain health. ${ }^{4}$ This includes public health systems that focus on prevention, health promotion, and addressing determinants of health alongside the healthcare/medical system. The relationship between public health and medicine, their institutions and practitioners, has evolved in each country depending on institutional histories, characteristics of medical education, and social boundaries among relevant disciplines. Most countries, such as the US, Germany, Turkey, and South Korea, have parallel systems that focus on medical care and public health. In addition to governing bodies that are tasked with coordination and planning functions, primary care providers may serve as a connecting tissue between the two systems and facilitate coordination across sectors, including housing, transport, nutrition, and education, that influence population health and well-being.

1 Laurie Garrett, "COVID-19: The Medium Is the Message." The Lancet, 395 (2020): 942-3. Garrett describes how the CDC has seen its overall budget plummet from about $\$ 11.5$ billion in fiscal year (FY) 2018 to $\$ 7.7$ billion in FY 2020. In addition, for FY 2021 further cuts are proposed by Robert Redfield, the CDC director. Another example of weakening governance is the decision of the Trump administration to eliminate the National Security Council's global health security and biodefense directorate in 2018.

2 Gary P. Pisano, Raffaella Sadun, and Michele Zanini, "Lessons from Italy's Response to Coronavirus." Harvard Business Review, March 27, 2020, https://hbr.org/2020/03/lessons-from-italys-response-tocoronavirus.

3 Devi Sridhar, "Britain Had a Head Start on Covid-19, But Our Leaders Squandered it." The Guardian, March 23, 2020.

4 WHO, Everybody Business: Strengthening Health Systems to Improve Health Outcomes - WHO's Framework for Action (Geneva: WHO Press, 2007). 


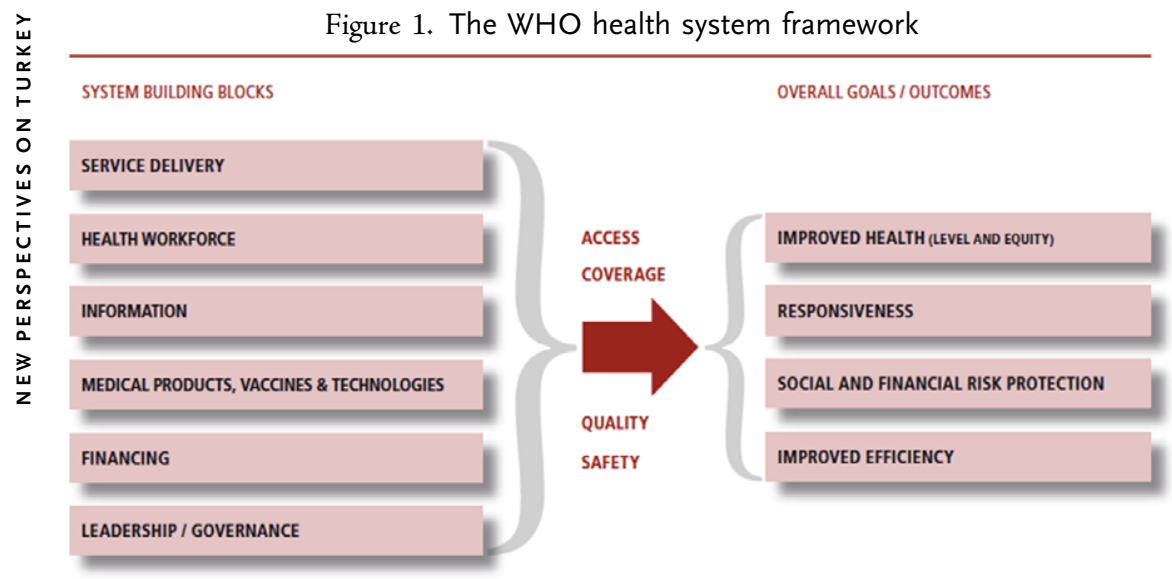

Source: WHO (2007).

One of the most commonly used tools to study healthcare systems is the WHO's "building blocks" framework that identifies six core components or blocks: (1) leadership and governance (stewardship); (2) service delivery; (3) health workforce; (4) health information system; (5) medical products, vaccines and technologies; and (6) health system financing (Figure 1). Recently, "people," referring not only to individual patients but also communities and civil society organizations, has been added as the seventh building block. Seen through this framework, COVID-19 raises serious questions about how we organize our healthcare systems and what we expect them to achieve. Here I will focus on a few issues with regards to delivery and will discuss issues pertaining to some of these building blocks in the next section.

In terms of service delivery, the balance among primary, secondary, and tertiary care has been shaped according to the dynamics of each healthcare system and COVID-19 demonstrated once again that we need a wellcoordinated care system. Given the pressure of high costs and concerns with quality, many countries were already considering ways of strengthening their primary care systems. During the pandemic, countries such as Singapore used their primary care systems effectively for testing, tracing, diagnosing, monitoring, and caring for their patients. ${ }^{6}$ Many primary care providers continued to manage care for patients with complex needs, such as those

5 WHO, Monitoring the Building Blocks of Health Systems: A Handbook of Indicators and Their Measurement Strategies (Geneva: WHO Press, 2010).

6 Wei Han Lim and Wei MonWong, "COVID-19: Notes From the Front Line, Singapore's Primary Health Care Perspective." The Annals of Family Medicine 18, no. 3 (2020): 259-61. 
with heart disease, diabetes, or hypertension, who might have avoided care out of fears that they might be exposed to COVID-19 in a healthcare setting. Primary care can also serve a key function of coordinating medical care, social care services, palliative care, and behavioral health services during and in the aftermath of the pandemic, and yet many countries failed to use their primary care systems effectively. ${ }^{7}$ For primary care to be effective in a pandemic response, we need to make sure to protect primary care providers with sufficient personal protective equipment (PPE), invest in new care models that rely on technology, such as telemedicine, and support financially struggling practices in countries such as the US.

Interestingly, at the other end of the health system or the highest level in the healthcare system pyramid, the ICU capacity has also proved highly beneficial in COVID-19 response (due to high numbers of cases requiring hospitalizations and weeklong ICU stays), as Turkey, Germany, ${ }^{8}$ and Belgium demonstrated. However, given the long-term discussions among health systems researchers about the cost and need for ICU beds, and resulting inefficiencies and waste, how do we assess the proper ICU capacity in the near future? How do we get the balance among primary, secondary, and tertiary levels right in a strong health system that operates effectively in normal times and is well prepared for a pandemic? Related to this question on capacity, many researchers are currently concerned with mortality and morbidity from illnesses not related to coronavirus. We know that many health care facilities closed during the pandemic, major programs focusing on tuberculosis (TB) or malaria were disrupted, and a lot of patients who were undergoing treatment had their care delayed or interrupted. ${ }^{9}$ The consequences of these disruptions can be serious and long lasting for patients and the health care systems that serve them: we can see a resurgence of vaccine-preventable illnesses or deaths from chronic illnesses. While the burden of unmanaged chronicle conditions is difficult to measure, a recent report by Stop TB Partnership ${ }^{10}$ suggests that

7 Tuba Agartan, "Cracks in COVID-19 Treatment Reveal Need to Bolster Primary Care." The Conversation, April 22, 2020; Sarah Mitchell, Victoria Maynard, Victoria Lyons, Nicholas Jones, and Claire Gardiner, "The Role and Response of Primary Care and Community Nursing in the Delivery of Palliative Care in Epidemics and Pandemics: A Rapid Review to Inform Practice and Service Delivery During the COVID-19 Pandemic." CEBM Blog, June 4, 2020, www.cebm.net/covid-19/ primary-carw-and-community-nursing/.

8 Sophia Schlette, Germany's Response to the Coronovirus Pandemic, Cambridge Blogs, 2020, www. cambridge.org/core/blog/2020/04/08/germanys-response-to-the-coronavirus-pandemic/.

9 Madhukar Pai and Jishnu Das, "Opinion: How Can India Address Big Surge for Health Care after Coronavirus Lockdown?" Devex, June 2, 2020, www.devex.com/news/opinion-how-can-indiaaddress-big-surge-for-health-care-after-coronavirus-lockdown-97382\#.XtbVDqVR0Z8.twitter.

10 Stop TB Partnership, The Potential Impact of the COVID-19 Response on Tuberculosis in High-burden Countries: A Modeling Analysis (2020), www.stoptb.org/assets/documents/news/Modeling\% 20Report_1\%20May\%202020_FINAL.pdf. 
each month of lockdown in India could cause an additional 40,000 TB deaths over the next five years.

Another important debate concerns courses of action proposed and/or implemented by public and private actors in healthcare systems. Once again COVID-19 brought questions regarding the balance between the public and private sectors and division of labor among governments and markets into stark relief. The UK government has recently announced that it would be relying on private companies for testing and contact tracing as part of the plan for reopening. Health systems scholars, however, highlighted the decades of cuts to the public healthcare system (the NHS) and marketization, which weakened the basic health infrastructure and crippled its capacity to carry out these duties. This weakening also resulted in fragmentation and lack of communication between national and local authorities. ${ }^{11}$

The role of the public sector and leadership capabilities of national leaders were once again questioned with regards to manufacturing the necessary equipment such as masks, personal protective gear, or ventilators: can governments repurpose manufacturing facilities or should they provide incentives to private manufacturers? How would international trade (importing/exporting) in medical equipment be regulated in the midst of a pandemic when everyone needs it? Similar questions can be asked about regulating private hospitals and clinics and using their capacity to cope with the pandemic, especially in countries such as Turkey or India, which recently expanded the share of the private sector in service provision. Interestingly, the large ICU capacity, alongside the necessary equipment, such as ventilators, and a highly trained health workforce in Turkey's private hospitals - which under normal conditions could be criticized for leading to overutilization, waste, and high costs - has proved valuable in the country's COVID-19 response. ${ }^{12}$ The Ministry of Health designated private hospitals that fit a certain criteria as "pandemic hospitals" and guaranteed that all services related to COVID-19 would be provided free of charge. ${ }^{13}$

Lastly and importantly, the COVID-19 experience allows us to think about the role of community. Long-term relationships with local communities built on trust matter not only for carrying out specific tasks such as using local

11 Felicity Lawrence, Juliette Garside, David Pegg, David Conn, Severin Carrell, and Harry Davies, "How a Decade of Privatisation and Cuts Exposed England to Coronavirus." The Guardian, May 31, 2020, www. theguardian.com/world/2020/may/31/how-a-decade-of-privatisation-and-cuts-exposed-england-tocoronavirus?CMP=share_btn_tw.

12 Evren Balta and Soli Özel, "The Battle Over the Numbers: Turkey's Low Case Fatality Rate." Institut Montaigne Blog, 4 May 2020, www.institutmontaigne.org/en/blog/battle-over-numbers-turkeyslow-case-fatality-rate; Gülsen Solaker, "Özel hastanelerde koronavirüs ile mücadele nasıl olacak?" Deutsche Welle Türkçe, March 24, 2020, www.dw.com/tr/\%C3\%B6zel-hastanelerde-koronavir\%C3\% BCs-ile-m\%C3\%BCcadele-nas\%C4\%B1l-olacak/a-52900074.

13 Solaker, "Özel hastanelerde koronavirüs ile mücadele nasıl olacak?" 
volunteers for contact tracing, but also for developing partnerships (1) to identify and deliver care for the vulnerable populations, (2) to promote safe distancing, mask wearing and other preventive efforts, and (3) to develop plans for the next stages of the pandemic with district and local health teams and community leaders. ${ }^{14}$

\section{Comparative health policy: insights and limits}

Among the various disciplines that engage in comparative analysis, International Relations (IR) has been concerned primarily with the question of "why" we look across the national borders for ideas and "what motivates policy-makers to engage in the policy transfer process." 15 This scholarship has provided rigorous analytical tools that help researchers explore how specific policies or tools (such as payment methods or electronic health records), ideas (such as value-based payments or managed care), norms (health care as a human right, Health for All), and positive or negative lessons move across the borders. ${ }^{16}$ Such diffusion is both inevitable and intentional: as Klein points out, policymakers do not want "to be caught wearing yesterday's ideas" ${ }^{\text {"17 }}$ and look across borders in search of models.

In the case of common challenges, such as economic crises, rising cost pressures, or communicable diseases, faced by many countries at the same time, the search for ideas gains additional importance. Policy actors scramble to learn about how the problem was experienced in other contexts, the solutions they developed, and try to devise their own responses. We have seen examples of this in the early days of COVID-19 when many policy actors carefully observed China's and Italy's experiences with the disease. The media was flooded with reports of which country did what, when, and how, and whether it worked. In the case of Turkey, some observers attributed its "successful" response to the time lag that allowed policymakers the opportunity to observe what was happening in other countries and develop their own plans. ${ }^{18}$ Others

14 Devi Sridhar and Genevie Fernandes, "Why Herd Immunity Won't Save India from COVID-19." Foreign Policy, May 5, 2020, https://foreignpolicy.com/2020/05/02/herd-immunity-india-coronaviruspandemic/.

15 David P. Dolowitz and David Marsh, "Learning from Abroad: The Role of Policy Transfer in Contemporary Policy-making." Governance, 13 (2000): 7.

16 Diane Stone, "Transfer Agents and Global Networks in the 'Transnationalization' of Policy." Journal of European Public Policy 11, no. 3 (2004): 545-66.

17 Rudolf Klein, "Learning from Others: Shall the Last Be the First?" Journal of Health Politics, Policy and Law 22, no. 5 (1997): 1267-78, 1275.

18 Menekse Tokyay, “Türkiye COVID-19'la mücadelede nasıl sonuç aldı, protokoller ve ilaçlar Avrupa'dan farklı mı?" Euronews, May 5, 2020, https://tr.euronews.com/2020/05/05/turkiyeCOVID-19-la-mucadelede-nas-I-sonuc-ald-protokoller-ve-ilaclar-avrupa-dan-farkl-m. 
criticized their governments for "squandering" the valuable time, as we saw in the case of the UK. ${ }^{19}$

Health policy researchers and public policy scholars quickly identified the need for evidence and initiated international collaborations to build country profiles summarizing pandemic responses. One of the organizers of such an initiative stated their objectives as helping people become "better informed about the response to the pandemic internationally, which might be particularly useful to policy makers in countries in which the threat has not yet been fully realized." 20 Another researcher based in Singapore and the London School of Health and Tropical Medicine, explained their intention for developing the country profiles as a means to learn "to adapt and influence the ability of health systems to respond with appropriate public health strategies in future outbreaks and other public health emergencies." 21

While comparison with others usually serves as a source of motivation for policy change, in times of crisis a failure to follow policy trends may have additional political consequences for policymakers who also have to respond to evidence from other, more "successful" countries. The daily rankings of key infection tracing measures such as the number of new infections and deaths as well as policy responses such as the number of tests conducted serve as platforms for assessing the performance of national policy actors comparatively. Britain's experience with COVID-19 provides one such example of added pressure on national governments. In the early weeks of the pandemic, the UK was being compared unfavorably with Germany, which conducted 500,000 tests a week. By mid-March, Boris Johnson's government had to reverse its earlier "herd immunity strategy" 22 in response to fierce criticisms from the scientific community and evidence from other countries.

Comparative analyses, especially those that explore diffusion, have significant limitations, too. Recent criticisms of the IR literature, from a broader social science perspective, have pointed out the rather uncritical treatment of the diffusion process and its limited focus on the processes of transmission. These limitations prevent this scholarship from distinguishing "learning about" from "learning from," that is, the lack of attention to how policies and practices

19 Sridhar, "Britain Had a Head Start."

20 Adam Oliver, quoted in LSE News, May 1, 2020, www.lse.ac.uk/News/Latest-news-from-LSE/2020/eMay-20/COVID-19-Complex-reasons-for-different-country-responses.

21 Richard Lane, "Profile: Helena Legido-quigley - Proponent of Health Systems Strengthening." Lancet 395 (2020): 1603.

22 Sarah Boseley, "Herd Immunity: Will the UK's Coronavirus Strategy Work?" The Guardian, 13 March 2020, www.theguardian.com/world/2020/mar/13/herd-immunity-will-the-uks-coronavirus-strategywork. 
may be altered throughout the processes of diffusion. ${ }^{23}$ Ideational scholars further expand the IR perspective through their in-depth analysis of the social construction of policy diffusion and success stories. ${ }^{24}$ Policy actors often use the policy ideas from other countries or the rankings to sell certain problem definitions, promote certain solutions to the public, build political support for their agendas, ${ }^{25}$ and enhance their "leverage with domestic opponents or hesitant political leaders." 26

Thus, cross-border learning is far from a neutral intellectual exercise ${ }^{27}$ or a technocratic process. Policy actors - within and outside of the government, including civil society organizations - often selectively assess and represent evidence from other countries, and they may (intentionally or unintentionally) misunderstand policy dynamics and specific details in other contexts. Their values, ideologies, prejudices, and economic assumptions shape "the object of their learning process and lessons drawn from specific policy experiments." 28 For instance, some recent anti-lockdown protests in the US used the slogan "Be like Sweden," referring to Sweden's COVID-19 strategy that enforced social distancing rules without a strict lockdown. ${ }^{29}$ Protesters in the US were more interested in advocating for their anti-lockdown position, and their ideologies shaped their perception of experiences of other countries. Thus, they used Sweden's experience as "ammunition" in policy debates to advance their position, ${ }^{30}$ while disregarding stark differences between the two countries involving their health care systems, social security systems, and characteristics of political culture such as state-society relations.

23 Mitchell Orenstein, "Mapping the Diffusion of Pension Innovation." In Pension Reform in Europe: Process and Progress, ed. Robert Holzmann, Mitchell Orenstein, and Michal Rutkowsk, 174 (Washington, DC: World Bank); Stone, "Transfer Agents," 547.

24 Daniel Béland, "The Politics of Social Learning: Finance, Institutions, and Pension Reform in the United States and Canada." Governance 19, no. 4 (2006): 559-83; Michell A. Orenstein, Privatizing Pensions: The Transnational Campaign for Social Security Reform (Princeton, NJ: Princeton University Press, 2008); Daniel Béland and Robert H. Cox, "Introduction: Ideas and Politics." In Ideas and Politics in Social Science Research, ed. Daniel Béland and Robert H. Cox (New York: Oxford University Press, 2011), 3-20; Daniel Béland, "Ideas and Institutions in Social Policy Research." Social Policy \& Administration 50, no. 6 (2016): 734-50.

25 Stone, "Transfer Agents," 548-9; Tuba I. Agartan, "Politics of Success Stories in the Path towards Universal Health Coverage: The Case of Turkey." Development Policy Review (2020), http://doi:10. 1111/DPR.12489.

26 Kurt Weyland, "Theories of Policy Diffusion: Lessons from Latin American Pension Reform." World Politics 57, no. 2 (2005): 273.

27 Klein, "Learning from Others."

28 Béland, "The Politics of Social Learning," 563.

29 H. J. Mai, "Stockholm Won't Reach Herd Immunity in May, Sweden's Chief Epidemiologist Says." May 25, 2020, NPR, www.npr.org/2020/05/25/861923548/stockholm-wont-reach-herd-immunity-in-maysweden-s-chief-epidemiologist-says.

30 Klein, "Learning from Others," 1270. 
Cross-border evidence can also be used to construct a successful image, given that many policymakers are interested in "victory, not illumination." 31 Examples of this abound in our responses to the COVID-19 pandemic, as policy actors assemble evidence to highlight their "successes." Despite contrary evidence, US President Trump touted that they had "tested more than every country combined" 32 while the Turkish government announced "mission accomplished"33 in May 2020 in the midst of lockdown measures. Therefore, comparative health policy methodology is particularly valuable in the context of the COVID-19 pandemic to understand the wide range of strategies available to policy actors, examine the processes of policy diffusion, and explore how policy actors use comparative information and success stories. However, given the emphasis on national policy actors and processes, this literature may overlook the importance of global actors, institutions, and ideas. This is true especially in the case of comparative analyses that focus on high-income countries, which may reproduce the colonial bias that the recommendations and guidelines developed by international organizations such as the WHO or the World Bank only apply to developing countries. The global health literature, however, is coming to terms more directly with this colonial legacy, as I discuss in the next section.

\section{Global health: legacies and opportunities}

Global health is a multidisciplinary field of study that builds on public health and international health but is distinct from them given its emphasis on the "health of the global population" as well as "interdependence" 34 among regions, countries, populations, institutions, and sectors. This definition, as evidenced and developed by the burgeoning literature, highlights two key features: (1) multilateralism as a political positioning, and (2) a multidisciplinary and multisectoral approach. The COVID-19 pandemic demonstrated how critical these two features have been to understanding the complex dynamics of a communicable disease that has impacted almost all countries in the world and to develop effective responses within the health system and beyond.

31 Ted Marmor, Richard Freeman, and Kieke Okma, "Comparative Perspectives and Policy Learning in the World of Health Care." Journal of Comparative Policy Analysis: Research and Practice 7 (2005): 334.

32 KHN, "Trump's Claim that U.S. Tested More than All Countries Combined Is 'Pants On Fire' Wrong." Kaiser Health News, May 1, 2020, https://khn.org/news/trumps-claim-that-u-s-tested-more-than-allcountries-combined-is-pants-on-fire-wrong/.

33 Selcan Hacaoğlu, "Turkey Declares '\#MissionAccomplished' Against Coronavirus." Bloomberg News, May 20, 2020, www.bloomberg.com/news/articles/2020-05-20/turkey-declares-missionaccomplishedagainst-coronavirus.

34 Julio Frenk, Octavio Gómez-Dantés, and Suerie Moon, "From Sovereignty to Solidarity: A Renewed Concept of Global Health for an Era of Complex Interdependence." Lancet 383 (2014): 95. 
Multilateralism as a political stance

As a field of study and practice, global health recognizes that shared problems are best solved by collective action and that the benefits of that action accrue to everyone. The emphasis on "shared problems" and "collective action" differentiates global health from international health. The field of international health, as it developed in universities, research centers, and philanthropic foundations in the United States and Western Europe during the twentieth century, used principles of public health to understand and solve health problems in developing countries such as infectious diseases, sanitation, malnutrition, and child and maternal health. ${ }^{35}$ International health programs embodied a structured set of positions whereby the donors in the North - fostered and represented by the Development Assistance Cooperation (DAC) - provided assistance to address the health needs of recipients in the South. ${ }^{36}$ Although global health still grapples with legacies of paternalistic philanthropy, colonial power asymmetries and ways of thinking, and/or affirmations of national selfinterest, multilateralism as a political stance reaffirms its mission and provides direction to its practice.

At the global level, commitment to multilateralism in the face of global pandemics is once again in the spotlight: on the one hand, there is the shocking decision of the Trump administration to pull the United States out of the $\mathrm{WHO}$, criticizing what it deemed as "the undue influence" of China over the institution and "its slow and nontransparent approach." ${ }^{37}$ Despite criticisms, the WHO has played a key role since December 2019, sharing information about SARS-CoV-2 and guiding mitigation strategies through the International Health Regulations. In line with its main mission, the organization coordinated data collection and research, collected the best evidence, and released policy guidance about what should be done. Therefore, while the Trump administration's attacks on multilateralism are well known - having withdrawn from the Paris Agreement on Climate Change, and cutting support to the UN Relief and Works Agency for Palestine Refugees in the Near East or

35 Michael H. Merson, Robert E. Black, and Anne J. Mills, International Public Health: Diseases, Programs, Systems, and Policies, 2nd edition (Sudbury, MA: Jones and Bartlett Publishers, 2006).

36 North and South here refer to the socio-spatial conception of the relationships between developed and developing countries that is characterized by inequality. Especially when used with the term "global," South is often used to describe "a collective transnational political identity [that] is produced through the shared experiences of exclusion, marginalisation, exploitation and disenfranchisement" (Luis Angosto-Ferrández cited in Thomas Muhr, "Beyond 'BRICS': Ten Theses on South-South Cooperation in the Twenty-first Century." Third World Quarterly 37, no. 4 (2016): 630-48, 638).

37 Thomas J. Bollyky and Yanzhong Huang, "The Multilateral Health System Failed to Stop the Coronavirus." Foreign Policy, March 10, 2020, https://foreignpolicy.com/2020/03/10/the-multilateralhealth-system-failed-to-stop-the-coronavirus/. 
the United Nations Population Fund - leaving the world's health agency during a pandemic and cutting financial support is shocking and goes beyond the earlier justifications of unilateralism such as national sovereignty and independence. At the time of writing this commentary it is still unclear how the withdrawal will unfold and what it would mean for the global pandemic response. However, what is clear is the major challenge facing the global health field: will it uphold multilateralism as a political stance, and as part of its mission and practice, or will it revert back to the international health rhetoric that allows room for unilateralism and exceptionalism under the foreign aid framework?

Taking this discussion one step further, I argue that we need to go beyond the mainstream framing of multilateralism as "collective solutions to common challenges." As a political stance, multilateralism can acquire new meanings in the current development context where the large number of "(re)emerging" donors and development partners from the global South are bringing not only additional financing and resources, but perhaps more importantly alternative development discourses and ideologies that emphasize solidarity, mutual benefits and complementarity, greater international equality, and fair trade. These partnerships and the principles they embody aim to reduce the power asymmetries among the parties ${ }^{38}$ and develop alternative regional and transcontinental relationships (examples include the India, Brazil and South Africa Facility for Poverty and Hunger Alleviation and the Shanghai Cooperation Organization). The global health field has a unique positioning to study this rapidly changing development architecture and provide new analytical tools that challenge the current constructions of North vs. South, First vs. Third, East vs. West, developed vs. developing. ${ }^{39}$ Some questions to explore concern China's role in the South-South flows or deepening Latin AmericanCaribbean partnerships in terms of their repercussions on environmental policy, health systems, social protection, education, food, etc. Turkey is one of these countries in the Global South playing a larger role in global health. New research can explore how its policy leaders engage with mainstream DAC practices while at the same time participating in the critical South-South cooperation discourse and partnering with many countries in the Middle East, Central Asia, and the African continent.

What I am suggesting here goes beyond an exploration of these key developments. Building a literature that acknowledges the voice and agency of the global South constitutes an important step in the development of the global health field and articulating its political positioning. Already there is a

38 Muhr, "Beyond 'BRICS'," 640.

39 James D. Sidaway, "Geographies of Development: New Maps, New Visions." The Professional Geographer 64, no. 1 (2012): 49-62; Emma Mawdsley, From Recipients to Donors : Emerging Powers and the Changing Development Landscape (London: Zed Books, 2012): 3-4. 
movement within the field calling for "decolonizing Global Health." Advocates challenge the power dynamics and representation within research partnerships, conferences, and other forms of academic collaborations. They call for a critical discourse around the colonial legacies in global health and demand representation of the global South in agenda-setting as well as decisionmaking. ${ }^{40}$

These initiatives acquire greater importance in the context of the COVID19 pandemic where experiences in the global South could inform policy decisions in the rest of the world. Some recent publications contrasted the COVID-19 response in Western Europe and North America with those in East Asia and sub-Saharan Africa. For instance, a New Yorker piece published in May 2020 quoted Joia Mukherjee - the chief medical officer for Partners in Health, a Boston-based nonprofit organization - who compared Belgium with its former colony, Rwanda, and highlighted the effectiveness of control measures in the latter. Similarly, John Nkengasong, the director of the Africa Centers for Disease Control and Prevention, underscored the health system preparedness and quick response: "Countries were shutting down and declaring states of emergency when no or single cases were reported. We have evidence to show that that helped a lot." 41 These analyses challenge power asymmetries in the production of knowledge as they demonstrate that, besides other factors, health system capacity and leadership explain why these countries so far have low numbers of COVID-19 cases. $^{42}$

Also benefiting from the critical comparative perspective discussed in the first section, this literature can help us identify factors that allowed for an effective response to COVID-19 and discuss how cross-border collaborations happen. For instance, it would be interesting to explore why the infectious disease response protocols (surveys, aggressive testing, contact tracing, and isolation) developed in the context of Ebola in West Africa with the help of United States Centers for Disease Control and Prevention - were not utilized effectively in Europe and the United States in the early days of the COVID-19 pandemic. This scholarship can also explore how the mainstream diffusion arguments that assume the movement of ideas from the North to the South can be challenged. There are already some examples where scholars arequestioning the

40 Andrew Green, "The Activists Trying to 'Decolonize' Global Health." Devex, May 21, 2019, www.devex. com/news/the-activists-trying-to-decolonize-global-health-94904.

41 Jina Moore, "What African Nations Are Teaching the West about Fighting the Coronavirus." The New Yorker, May 15, 2020, www.newyorker.com/news/news-desk/what-african-nations-are-teachingthe-west-about-fighting-the-coronavirus.

42 Health system capacity includes many components ranging from contact tracing to treatment. In addition to aggressive contact tracing and isolation, countries such as Ethiopia, South Africa, and Uganda conducted surveys, documenting symptoms, identifying at risk groups, tracing the spread of the disease, and identifying positive cases. 
appropriateness, for some low-income countries, of adopting the prescribed solutions, such as complete lockdowns, that work in Italy or Spain. ${ }^{43}$ Other scholars have highlighted how "the highly conditioned donor mindset of the structural adjustment era" 44 and loan practices have reduced "the fiscal space for investment in health, limit staff expansion of doctors and nurses, and lead to budget execution challenges in health systems." ${ }^{\prime 45}$ In the recent New Yorker piece mentioned above, Mukherjee discusses the consequences of the brain drain and underinvestment in health systems infrastructure: "Years of neoliberalism has basically made it impossible for African countries to build a treatment infrastructure that would include I.C.U. beds and oxygen." ${ }^{46}$

I do recognize that this is by no means an easy task. Even those countries that publicly support multilateralism still operate within an international health architecture that believes in power asymmetries and different paths for the North and the South. For instance, in March 2020 the chief medical officer for England, Dr. Jenny Harries, was quoted as stating that WHO guidelines for COVID-19 testing did not apply to the UK's "extremely well-developed public health system" ${ }^{\prime 7}$ but were meant for low-income countries. In addition, the studies mentioned above demonstrating the accumulated experience outside of Western Europe and North America - in the African continent with Ebola and HIV/AIDS, East and Southeast Asia with SARS and MERS, South America with Zika - were not necessarily used in the North to develop policy responses to COVID-19. Undoubtedly, the transfer of policy expertise and guiding values from the South to North challenges the colonial and DAC notions of dependency of the South to the North.

\section{Multidisciplinarity and health systems research}

Global health is multidisciplinary by definition: faced with complex challenges ranging from infectious diseases to chronic conditions, from malnutrition to planetary health, global health relies on cooperation among many disciplines

43 Amanda Glassman, Kalipso Chalkidou, and Richard Sullivan, "COVID-19 Response in Low-Income Countries." CGDEV blog, April 2, 2020, www.cgdev.org/blog/does-one-size-fit-all-realisticalternatives-COVID-19-response-low-income-countries\#.XoXij3JCfTM.twitter.

44 Richard Manning, The DAC As a Central Actor in Development Policy Issues: Experiences over the Past Four Years. Discussion Paper 7/2008. (Bonn: German Development Institute, 2008), 3, https://nbnresolving.org/urn:nbn:de:0168-ssoar-193949.

45 Thomas Stubbs, Alexander Kentikelenis, David Stuckler, Martin McKee, and Lawrence King, "The Impact of IMF Conditionality on Government Health Expenditure: A Cross-national Analysis of 16 West African Nations." Social Science and Medicine 174 (2017): 220.

46 Moore, "What African Nations".

47 Abraar Karan and Mishal Khan, "The Ghosts of Colonialism Are Haunting the World's Response to the Pandemic." NPR, May 29, 2020, www.npr.org/sections/goatsandsoda/2020/05/29/862602058/opinionthe-ghosts-of-colonialism-are-haunting-the-worlds-response-to-the-pandem?utm_campaign=storyshare \&utm_source=twitter.com\&utm_medium=social. 
and sectors that are beyond the traditional boundaries of the health sector. While in practice natural sciences and clinical perspectives still dominate global health discussions and proposed solutions, the value and contribution of the social sciences and humanities are increasingly recognized. Yet, global health should show more commitment to studying the political, social, economic, commercial, and behavioral determinants and balance this approach with its long-term fascination with quick, narrow, technical solutions.

One of the key divisions that have shaped the field of international health, and now global health, concerns disagreement over the key challenges and how to address them. On the one side, there are the advocates of a vertical approach who identify specific diseases, such as malaria or HIV/AIDS, as the main challenges and develop responses that target that disease directly, often bypassing existing health systems. International health has long suffered from this narrow or "reductionist" perspective that emphasized technical solutions and vertical programs dedicated to control of specific diseases in developing countries. ${ }^{48}$ On the other side, horizontal/systems-based approaches emphasize building a system that responds to many challenges, stress prevention, and encouraging collaboration with other sectors. Especially since the Second World War, the principles of intersectoral collaboration and rural development were relegated to a secondary status, and vertical programs aimed at treating specific diseases such as malaria, yaws, or smallpox occupied center stage. Despite periods of revival, especially with the Alma Ata Declaration of 1978, horizontal approaches were shadowed by the medical/treatmentfocused approach that dominated these vertical programs and family-planning services over the preventive approach. ${ }^{49}$

This dynamic between the horizontal and vertical perspectives continues to shape the debates in global health research. The pendulum swung toward the vertical programs once again during the 1990s, as seen in the proliferation of disease-specific programs in developing countries, particularly the Global Vaccine Alliance created in 2000, the Global Fund to Fight AIDS, TB and Malaria, and the United States President's Emergency Plan for AIDS Relief. However, since the late 2000s horizontal approaches are gaining ground within the WHO and the broader global health agenda. Interest in health systems strengthening grew - within academia and the agendas of many organizations involved in global health - in the context of first the Millennium Development Goals and then the Sustainable Development Goals (SDGs): a

48 Frenk et al., "From Sovereignty," 94.

49 Gill Walt and Lucy Gilson, "Can Frameworks Inform Knowledge about Health Policy Processes? Reviewing Health Policy Papers on Agenda Setting and Testing Them Against a Specific PrioritySetting Framework." Health Policy and Planning 29 (2014): 356-7. 
growing body of evidence showed that poorly functioning health systems were responsible for slow progress in achieving key health targets. ${ }^{50}$

Universal health coverage (UHC) represents the latest horizontal, systemsbased initiative in a series of international commitments to improve the wellbeing of individuals and communities. Defined as all people having "access, without discrimination, to nationally determined sets of the needed promotive, preventive, curative, rehabilitative and palliative essential health services, and essential, safe, affordable, effective and quality medicines and vaccines, while ensuring that the use of these services does not expose the users to financial hardship, with a special emphasis on the poor, vulnerable, and marginalized segments of the population," ${ }^{51}$ UHC provides a set of objectives for the strengthening of health systems. ${ }^{52}$ Its importance has been explained in terms of an "umbrella" that brings disparate actors and issues together, "a driver of social justice, human rights and inclusive economic growth," $" 3$ and as a "movement."

Seen from this division between the vertical and horizontal approaches, how can we analyze the response to the COVID-19 pandemic globally and within countries? Given that it is a contagious disease with unique characteristics - hence the "novel" classification - should we focus on creating vertical programs aimed at examining the disease and develop treatment protocols, new drugs, and vaccines? Alternatively, widespread issues with the COVID-19 response of various countries can be seen as an evidence of weak health systems capacity that presents bottlenecks to achieving effective control measures. Using the WHO's Health Systems Framework, we can see the slow and uncoordinated response as a sign of weak leadership/governance capacity, lack of protective gear and testing as an issue with technology, and shortage of providers and ICU beds as evidence of workforce and delivery problems. I argue that the bealth systems strengthening framework provides a good tool to critically analyze the different components of a health system and how they interact - or fail to interact - with each other under normal circumstances as well as during a public health crisis. Besides measuring system performance in terms of prevention and treatment, this approach allows us to discuss

50 Tamara Hafner and Jeremy Shiffman, "The Emergence of Global Attention to Health Systems Strengthening." Health Policy and Planning 28 (2013): 41-50.

51 UN, Political Declaration of the High-level Meeting on Universal Health Coverage - Universal Health Coverage: Moving Together to Build a Healthier World (New York: United Nations, 2019), www.un. org/pga/73/wp-content/uploads/sites/53/2019/07/FINAL-draft-UHC-Political-Declaration.pdf.

52 Joseph Kutzin and Susan P. Sparkes, "Health Systems Strengthening, Universal Health Coverage, Health Security and Resilience." Bulletin of the World Health Organization 94, no. 2 (2016).

53 UN, Summary By the President of the General Assembly of the Interactive Multi-stakeholder Hearing As Part of the Preparatory Process for the United Nations High-level Meeting on Universal Health Coverage (New York: United Nations, 2019).

$54 \mathrm{WHO}$, Address by Dr Margaret Chan, Director-General, to the Seventieth World Health Assembly (Geneva, 2017), https://apps.who.int/iris/handle/10665/274658. 
system-level problems such as lack of coordination between the public health agencies and the healthcare system, fragmentation within the healthcare system, and the balance between the public and private sectors.

\section{Concluding thoughts: The UHC agenda offers a path forward}

COVID-19 demonstrated how quickly viruses could spread given the dense connections among countries and regions, and could have devastating consequences for the health and well-being of populations, the global economy, and trade relations. It has also shown the limitations of comparative health policy literature, with its emphasis on national policy actors and processes, especially in the context of high-income countries. In the years to come, with possibly more pandemics in the horizon alongside challenges associated with noncommunicable diseases, poverty, inequality, and malnutrition, it can be expected that the field of global health will grow. Yet, the global health field is also challenged to consider its mission, political standing on multilateralism, changing relationships between North and South, and its commitment to a multidisciplinary approach. As we adjust our strategies to control the spread of the virus, provide treatments to patients diagnosed with the illness, and develop new vaccines and treatment protocols, scholars studying health systems need to tailor our theoretical frameworks, ask critical questions about health systems and public health infrastructure, and explore how they relate to other sectors. In this process the UHC agenda and SDGs more broadly can inform and shape our responses that emphasize equity and justice, pay special attention to vulnerable populations, and consider the broader implications for poverty and human development.

\section{References}

Agartan, Tuba I. "Politics of Success Stories in the Path towards Universal Health Coverage: The Case of Turkey." Development Policy Review (2020). http://doi:10.1111/DPR.12489.

Béland, Daniel. "The Politics of Social Learning: Finance, Institutions, and Pension Reform in the United States and Canada." Governance 19, no. 4 (2006): 559-83.

—. "Ideas and Institutions in Social Policy Research." Social Policy \& Administration 50, no. 6 (2016): 734-50.

Béland, Daniel and Robert H. Cox. "Introduction: Ideas and Politics." In Ideas and Politics in Social Science Research, edited by Daniel Béland and Robert H. Cox, 3-20. New York: Oxford University Press, 2011. Dolowitz, David P. and David Marsh. "Learning from Abroad: The Role of Policy Transfer in Contemporary Policy-Making." Governance, 13 (2000): 5-23.

Frenk, Julio, Octavio Gómez-Dantés, and Suerie Moon. "From Sovereignty to Solidarity: A Renewed Concept of Global Health for an Era of Complex Interdependence." Lancet 383 (2014): 94-7.

Garrett, Laurie. "COVID-19: The Medium Is the Message." The Lancet, 395 (2020): 942-3. 
Hafner, Tamara and Jeremy Shiffman. "The Emergence of Global Attention to Health Systems Strengthening." Health Policy and Planning 28 (2013): 41-50.

Klein, Rudolf. "Learning from Others: Shall the Last Be the First?" Journal of Health Politics, Policy and Law 22, no. 5 (1997): 1267-78.

Kutzin, Joseph and Susan P. Sparkes. "Health Systems Strengthening, Universal Health Coverage, Health Security and Resilience." Bulletin of the World Health Organization 94, no. 2 (2016).

Lane, Richard. "Profile: Helena Legido-Quigley - Proponent of Health Systems Strengthening." Lancet, 395 (2020): 1603.

Lim, Wei Han and Wei MonWong. "COVID-19: Notes from the Front Line, Singapore's Primary Health Care Perspective." The Annals of Family Medicine 18, no. 3 (2020): 259-61.

Manning, Richard. The DAC As a Central Actor in Development Policy Issues: Experiences over the Past Four Years. Discussion Paper 7/2008. Bonn: German Development Institute, 2008. https://nbn-resolving. org/urn:nbn:de:0168-ssoar-193949.

Marmor, Ted, Richard Freeman, and Kieke Okma. "Comparative Perspectives and Policy Learning in the World of Health Care." Journal of Comparative Policy Analysis: Research and Practice 7 (2005): 331-48.

Mawdsley, Emma. 2012. From Recipients to Donors: Emerging Powers and the Changing Development Landscape. London: Zed Books.

Merson, Michael H., Robert E. Black, and Anne J. Mills. International Public Health: Diseases, Programs, Systems, and Policies, 2nd edition. Sudbury, MA: Jones and Bartlett Publishers, 2006.

Muhr, Thomas. "Beyond 'BRICS': Ten Theses on South-South Cooperation in the Twenty-First Century." Third World Quarterly 37, no. 4 (2016): 630-48.

Orenstein, Michell A. "Mapping the Diffusion of Pension Innovation." In Pension Reform in Europe: Process and Progress, edited by Robert Holzmann, Mitchell Orenstein, and Michal Rutkowsk, 171-94. Washington, DC: World Bank, 2003.

—. Privatizing Pensions: The Transnational Campaign for Social Security Reform. Princeton, NJ: Princeton University Press, 2008.

Sidaway, James D. "Geographies of Development: New Maps, New Visions." The Professional Geographer 64, no. 1 (2012): 49-62.

Stone, Diane. "Transfer Agents and Global Networks in the 'Transnationalization' of policy." Journal of European Public Policy 1, no. 3 (2004): 545-66.

Stop TB Partnership. The Potential Impact of the COVID-19 Response on Tuberculosis in High-burden Countries: A Modeling Analysis (2020). www.stoptb.org/assets/documents/news/Modeling\% 20Report_1\%20May\%202020_FINAL.pdf.

Stubbs, Thomas, Alexander Kentikelenis, David Stuckler, Martin McKee, and Lawrence King. "The Impact of IMF Conditionality on Government Health Expenditure: A Cross-National Analysis of 16 West African Nations." Social Science and Medicine 174 (2017): 220-7.

UN. Political Declaration of the High-level Meeting on Universal Health Coverage - Universal Health Coverage: Moving Together to Build a Healthier World (2019). www.un.org/pga/73/wp-content/ uploads/sites/53/2019/07/FINAL-draft-UHC-Political-Declaration.pdf.

- Summary by the President of the General Assembly of the Interactive Multi-stakeholder Hearing As Part of the Preparatory Process for the United Nations High-level Meeting on Universal Health Coverage. New York: United Nations, 2019.

Walt, Gill and Lucy Gilson. "Can Frameworks Inform Knowledge about Health Policy Processes? Reviewing Health Policy Papers on Agenda Setting and Testing Them Against a Specific Priority-Setting Framework." Health Policy and Planning 29 (2014): 356-7.

Weyland, Kurt. "Theories of Policy Diffusion: Lessons from Latin American Pension Reform." World Politics 57, no. 2 (2005): 262-95.

WHO. Everybody Business: Strengthening Health Systems to Improve Health Outcomes - WHO's Framework for Action. Geneva: WHO Press, 2007.

- Monitoring the Building Blocks of Health Systems: A Handbook of Indicators and Their Measurement Strategies. Geneva: WHO Press, 2010. 